\title{
Nutritional assessment of children suffering from Autism
}

Aniqa Amjad ${ }^{1}$, Aiman Ijaz ${ }^{1}$, Mahtab Bader ${ }^{1}$, Ayesha Arshad ${ }^{1}$, Maryam Shahzadi ${ }^{1}$, Mehvish Amjad ${ }^{2}$, Anjum Javed ${ }^{3}$, Sadaf Javaria ${ }^{4}$ and Muhammad Nadeem ${ }^{*}$

1. University Institute of Diet and Nutritional Sciences, Faculty of Allied Health Sciences, University of LahorePakistan

2. Riphah International University, Lahore Campus-Pakistan

3. Wheat Research Institute, Ayub Agricultural Research Institute, Faisalabad-Pakistan

4. Institute of Food Science and Nutrition, Gomal University, D.I.Khan-Pakistan

5. Institute of Food Science and Nutrition, University of Sargodha, Sargodha-Pakistan

*Corresponding author's email: mnadeemft@gmail.com

Citation

Aniqa Amjad, AimenIjaz, Mahtab Bader, Ayesha Arshad, Maryam Shahzadi, MehvishAmjad, AnjumJaved, Sadaf Javaria and Muhammad Nadeem. Nutritional assessment of children suffering from Autism. Pure and Applied Biology. Vol. 10, Issue 4, pp1166-1172. http://dx.doi.org/10.19045/bspab.2021.100123

\begin{tabular}{llll}
\hline \hline Received: 16/11/2020 & Revised: 22/01/2021 & Accepted: 29/01/2021 & Online First: 03/02/2021 \\
\hline \hline
\end{tabular}

\section{Abstract}

The research was aimed to determine the nutritional assessment of children suffering from autism. Autism is a neuro-developmental disorder comprising of many problems and different levels of symptoms including speaking problems, behavioral and mental issues and difficulty in social interactions and many more. Hence, it is also called Autism Spectrum Disorder (ASD). A crosssectional study was performed on 237 autistic children for a period of 4 months in different institutes and day care centers. Data was analyzed using SPSS version 25.0. Frequencies and percentages were calculated by descriptive analysis. The study concluded that majority of the participants were underweight. Epilepsy was not found common in these children. Most of these participants were found to be aggressive, on long term medication and dealing with depression. Their eating habits included use of less than 5 glasses of water per day, less consumption of meat and poultry. Additionally, fruits and vegetable intake was good. Sugar consumption was exceeding daily requirements. Therefore, parents or caretakers of autistic children should mainly pay attention to the sugar intake of children to adopt healthy eating habits and improve nutritional status. This study will help the scientific community to care autistic children in the society by providing basic assessment.

Keywords: Aggressive behavior; Autism; Behavioral interactions; Children; Epilepsy; Nutrition

\section{Introduction}

Autism is a neurobehavioral condition which includes impairments in communication and social interaction and language skills combined with firm repetitive behavior. Due to the bundle of symptoms, this condition is known as autism spectrum disorder (ASD) and it is not easy to understand this disability [1]. The functional imagining studies suggested a model in which the frontal lobe of brain are connected with the higher order association areas which are disconnected during development. This concept has been observed in the autistic cases [2]. Autism 
spectrum disorder is closely related to pervasive development disorders (PDD), Rett disorder, childhood disintegrative disorder, Asperger disorder and autistic disorder [3]. Different diagnostic areas showed that in United Kingdom population size of autistic cases is 78,000 with the age of 8-10 and affected by autism are 32, in Sweden sample size is 69,000 with the age of $0-20$ and affected are 39, in Ireland population size is 65,000 with the age of 8-10 and affected are 28 , in Portugal size is 67,795 with the age of 6-9 and 115 are affected [4]. The prevalence of autism spectrum disorder in south Asia is $0.09 \%$, in India the rate is $0.07 \%$, In Dhaka city there is high prevalence of autism which is $3 \%$, in Sri Lanka more than 1 child is affected by the autism out of 93 children [5]. The hospital based data showed the prevalence of autism in different cities of Pakistan. In Karachi the sample size is 290 and $2.4 \%$ are affected, in Rawalpindi the sample size is 169 and 5.3\% are affected and in Lahore sample size is 1000 and $3.2 \%$ are affected [6]. A study done in preschool age children and suggested that 30 to 40 percent of autistic children are also facing attention deficit hyperactivity disorder (ADHD) in which they find difficulties in pay attention or focus on a single object, wait to react during discussion, trouble in playing and doing activities quietly. This study also suggested that if there is ADHD then symptoms of autism will appear [7]. Autistic children cannot understand the attitudes, behaviors, emotions and feeling of others. They don't have the ability to judge that what other person is thinking about them. But sometimes boys with autism show affective empathy towards other people [8]. Autistic children have the symptoms of gastrointestinal problems, abdominal pain, constipation and diarrhea [9].These children also showed the symptoms of malnutrition, the children with the age of 2-5 years are overweight and obese while children with the age of 5-11 are underweight [10]. In the results of comparison studies autistic children have a lot of deficiencies with high body mass index [11]. Genes are the primary etiology of autism. A lot of genes are responsible for the causing autism found in last 10 years by studying $10-20 \%$ of autism cases. These findings have provided us the information about the pathophysiology of autism spectrum disorder [12]. In a study monozygotic twins (that developed from single zygote, divides and form two embryos) showed the occasion of autism $60 \%$ to $90 \%$ and in dizygotic twins (each twin developed from a separate egg and each egg is fertilized by its own sperm cell) showed the occasion of autism $0 \%$ to $30 \%$ [13]. Twin studies displayed, genes play $38 \%$ role in autism while environmental factors play $58 \%$ role in autism spectrum disorder. Parental interact with organic phosphorus pesticides can lad towards ASD and ADHD. Environmental factor is the major etiology of autism [14]. Epilepsy is an additional clinical condition with autism. In result of recent study there are 20-25\% chances that both disorders appeared together [15]. As compared to other children these children suffer from higher rates of sleep problems and insomnia ranges $40 \%$ to $80 \%$ [16]. Children with autism are highly selective in food choices, refused food and have high frequency intake of single food. That's why suffered from nutritional adequacies [17]. Autistic children refuse new teases and have different meal time problems. They have significantly higher meal time problems as compared to their siblings while living in same social environment. Autistic children have $13.3 \%$ meal time problems while siblings have $5.0 \%$ problems [18]. The main objective of this study is to evaluate or assess the nutritional status of children suffering from autism.

\section{Materials and Methods}

The purpose of this study was aimed to determine the nutritional assessment of 
children suffering from autism. A crosssectional study was carried out at Lahore Institute of Special Care and Attention (LISCA) hospital for period of 4 months. Total 237 samples of autism were selected. Non-probability convenient sampling technique was applied to select the participant. The rules and regulation of ethical committee of University of Lahore were followed while conducting the result.Written informed consent was taken from all the patients. After taking informed written consent, data were be collected by the researcher with the help of pre-tested data collection tool (Questionnaire/Pro-forma). Data were be collected according to the variables of the questionnaire which are as follows: Demographic data were be taken from the participants. Questions were be asked directly attending the outdoor department or admitted in hospitals. Data were tabulated and analyzed with the help of SPSS (Statistical Package for the Social Sciences) version 25.0 and Microsoft excel. The data were reported during descriptive and inferential statistics. The quantitative variables like age, etc. were assessed by using mean standard deviation and standard errors.
The qualitative variables were report using percentages and frequencies

\section{Results}

Results showed that $25.3 \%$ children ranged between 3 to 8 years, $25.3 \%$ children ranged between 3 to 8 years. $19.8 \%$ children ranged between 15 to 20 years. The prevalence $54.9 \%$ was high in children with age of 9 to 14 years as shown in the (Fig. 1).

The results showed that, majority $64.1 \%$ children were diagnosed with underweight. $27.8 \%$ children were diagnosed with normal weight. $3.8 \%$ children were diagnosed with overweight. $2.5 \%$ children were diagnosed with obese. $1.7 \%$ children were diagnosed with grade 1 obesity (Fig. 2).

Result showed that $73.8 \%$ children had anxiety and $26.2 \%$ children didn't had anxiety (Fig. 3).

Out of 100 participants, $28.3 \%$ were not consuming red meat / mutton at all, $21.5 \%$ patients were consuming beef / mutton 1-2 times per week, $15.6 \%$ children consumed beef / mutton 3 to 4 times per week and $31.2 \%$ children consumed beef / mutton once a week. $3.4 \%$ children consumed beef /mutton daily as shown in (Fig. 4).

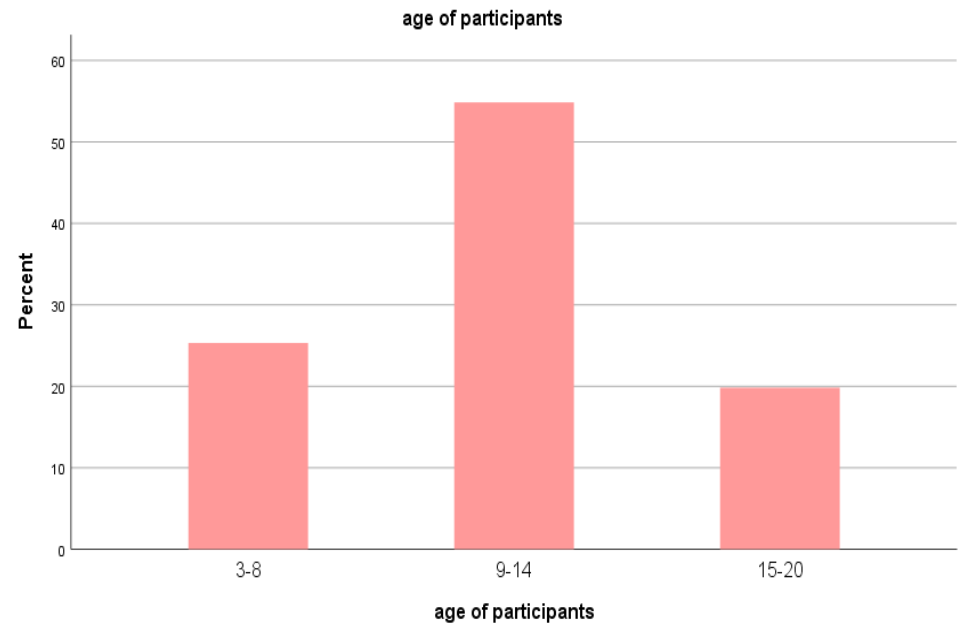

Figure 1. Frequency distribution of age in Autistic children 


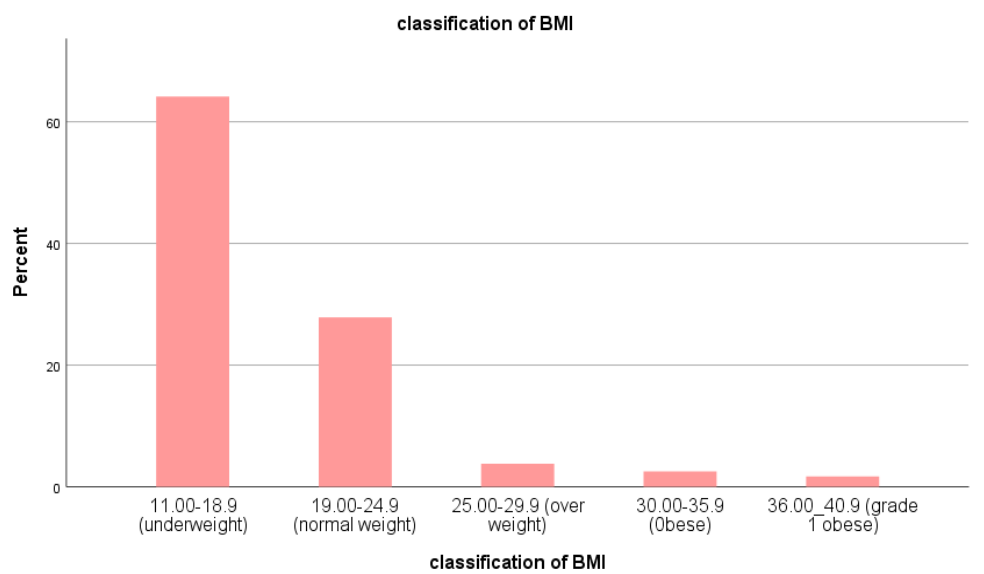

Figure 2. Classification of BMI of Autistic children

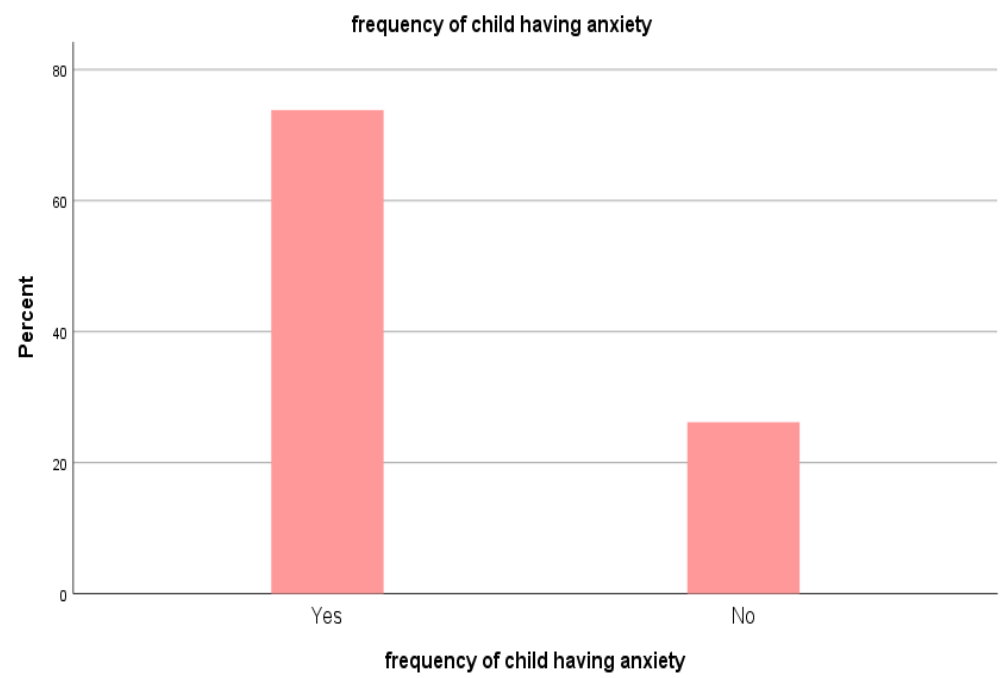

Figure 3. Frequency of Autistic children having anxiety

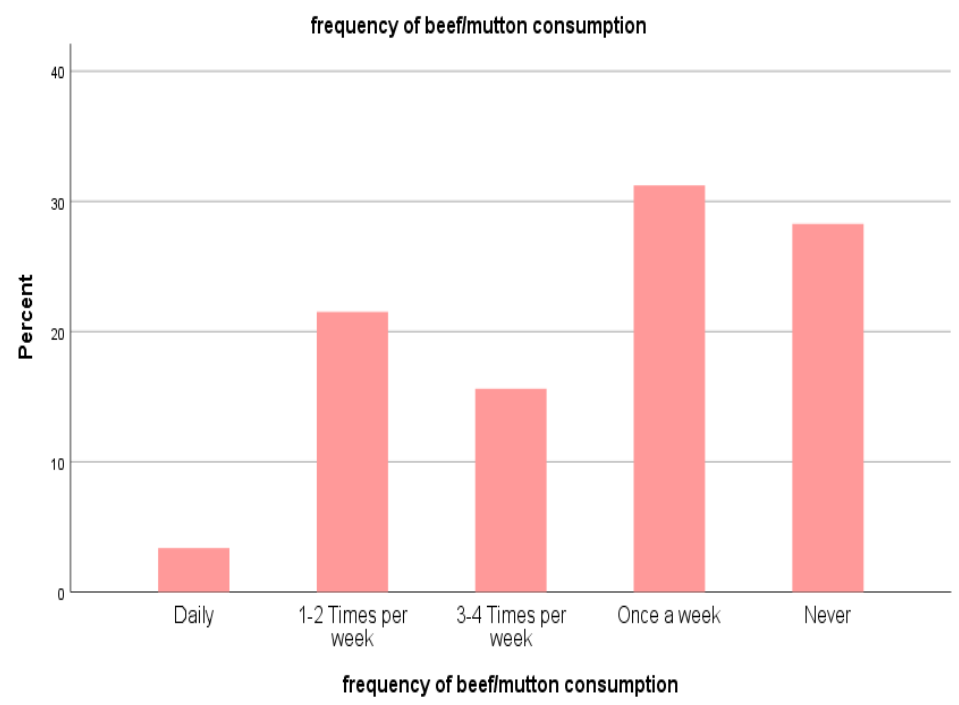

Figure 4. Frequency of beef/mutton consumption in Autistic children 


\section{Discussion}

The study was conducted to assess the effect of different dietary patterns of autistic children. According to the present assessment conducted in Lahore and Okara the children suffering from autism is $74.3 \%$. Previous study supported current assessment, which has been conducted in hospitals of different cities. In Karachi, the among sample of 290 people, 7 patients were suffering from autism, in Rawalpindi sample size was 169 and 9 patients were suffering from autism and in Lahore sample size was 1000 and 32 patients were suffering from autism [19].

In current assessment which is conducted in Lahore and Okara the children diagnosed with autism have $72.2 \%$ interaction problems toward their family and friends. In the clinical and experimental study showed that the children with the autism displayed less desire for the social interaction as compared to the normal developing children [20].

Assessment indicated that $74.3 \%$ children showed low response to command, $70 \%$ children showed restricted behaviors to command, $70.5 \%$ children have speaking problems, $79.7 \%$ children have aggressive behavior and $62.4 \%$ children facing depression. A study done by Nabil Hassan El-Ghoroury suggested that autistic children show group of behavioral symptoms and also displayed restricted behavior and impairment in language and socialization. In this study it was also suggested that these behaviors can be modified by psychotherapies, by the clinical services and trained their parents and caregivers [21].

In current evaluation $28.7 \%$ autistic children have sedentary life style. In a study, there were 53 autistic children compared with 58 typically developing children within the age group of 3-11 years. Study showed that autistic children spent one hour more in sedentary condition on weekdays and data about their routine was conducted by their parents and caregiver. Autistic children mostly enjoy screen time, this study also suggested that they spent 2.5 hours on screen daily while typically developing children spent 1.6 hours daily on screen [22].

Assessment showed that $70 \%$ children showed restricted behaviors to diet. Research done by SobhanaRanjan highlighted that children with ASD were showing nutritionally vulnerable behaviors because they were selective or had picky eating patterns which lead them towards restricted intakes [23].

Finding showed that $3.8 \%$ children are overweight. In previous study, hospital based data in which 273 autistic children were involved. According to the result $17.16 \%$ had BMI in range of overweight and $21.89 \%$ had BMI in the range of obesity $[4,7]$. A research conducted in Spain demonstrated that a gluten- as well as casein-free diet lead to weight loss plus lower BMI. Evaluation conducted in Lahore and Okara 64\% Children with ASDs are more frequently underweight. A cross-sectional study was done among the 128 autistic pre-school children within the age group of 3-5 years. Results suggested that most common type of malnutrition was underweight, wasting and stunting. Underweight and wasting were significantly higher in boys as compared to girls and wasting was higher in girls [24].

According to present assessments $22.4 \%$, $29.1 \%, 37.6 \%, 37.6 \%, 28.3 \%, 20.3 \%$ and $37.1 \%$ children are consuming spinach, salad, potatoes, cucumber, carrots and radish respectively. Similarly $27.0 \%, 37.1 \%, 24.9 \%$ and $25.3 \%$ autistic children are consuming mango, guava, apple and peach respectively. In a previous comparison study, 53 autistic children and 58 typically developing children. And results showed that autistic child were consuming significantly more sweetened beverages and snack foods as compared to normal children. Autistic children consuming vegetables and fruits 
significantly less than the typically developing children [25].

\section{Conclusion}

The study concluded that majority of the children suffering from autism were underweight. Most of these participants were found to be aggressive, on long term medication and dealing with depression. About $73.8 \%$ children had anxiety. Epilepsy was not found common in these children. Assessment showed that $70 \%$ children showed restricted behaviors to diet. Their eating habits included use of less than 5 glasses of water per day, less consumption of meat and poultry. Additionally, fruits and vegetable intake was good. Sugar consumption was exceeding daily requirements. Therefore, parents or caretakers of autistic children should mainly pay attention to the sugar intake of children to adopt healthy eating habits and improve nutritional status.

\section{Authors' contributions}

Conceived and designed the experiments: A Amjed \& A Ijaz, Performed the experiments: AAmjed, A Ijaz, M Bader \& A Arshad, Contributed reagents/ materials/ analysis tools: M Shahzadi, M Amjad, A Javed \& S Javaria, Wrote the paper: A Amjed, AIjaz \& M Nadeem.

\section{References}

1. American Psychiatric Association (2013). Diagnostic and statistical manual of mental disorders (DSM-5®). Am Psychiatric Pub, pp. 175.

2. Geschwind DH \& Levitt P (2007). Autism spectrum disorders: developmental disconnection syndromes. Curr Opin in Neurobiol 17(1): 103-111.

3. Nabavi SF, Braidy N, Gortzi O, SobarzoSanchez E, Daglia M, Skalicka-Woźniak K \& Nabavi SM (2015). Luteolin as an anti-inflammatory and neuroprotective agent: A brief review. Brain Res Bull 119: 1-11.
4. Elsabbagh M, Divan G, Koh YJ, Kim YS, Kauchali S, Marcín C \& Yasamy MT (2012). Global prevalence of autism and other pervasive developmental disorders. Autism Res 5(3): 160-179.

5. Hossain MD, Ahmed HU, Uddin MJ, Chowdhury WA, Iqbal MS, Kabir RI \& Hossain SW (2017). Autism Spectrum disorders (ASD) in South Asia: a systematic review. BMC Psych 17(1): 17.

6. Patel VB, Preedy VR \& Martin CR (Eds.) (2014). Comprehensive guide to autism. Springer New York.

7. Leitner Y (2014). The co-occurrence of autism and attention deficit hyperactivity disorder in children-what do we know. Frontiers in Human Neurosci 8: 268.

8. Jones AP, Happé FG, Gilbert F, Burnett S \& Viding E (2010). Feeling, caring, knowing: different types of empathy deficit in boys with psychopathic tendencies and autism spectrum disorder. $J$ of Child Psychol and Psych 51(11): 1188-1197.

9. McElhanon BO, McCracken C, Karpen S \& Sharp WG (2014). Gastrointestinal symptoms in autism spectrum disorder: a meta-analysis. Pedia 133(5): 872-883.

10. Hyman SL, Stewart PA, Schmidt B, Lemcke N, Foley JT, Peck R \& James SJ (2012). Nutrient intake from food in children with autism. Pedia 130 (Suppl 2): S145-S153.

11. Shmaya Y, Eilat-Adar S, Leitner Y, Reif S \& Gabis L (2015). Nutritional deficiencies and overweight prevalence among children with autism spectrum disorder. Res in Devel Disabil 38: 1-6.

12. Ander BP, Barger N, Stamova B, Sharp FR \& Schumann CM (2015). Atypical miRNA expression in temporal cortex associated with dysregulation of immune, cell cycle, and other pathways 
in autism spectrum disorders. Mol Autism 6(1): 1-13.

13. Robinson EB, Koenen KC, McCormick MC, Munir K, Hallett V, Happé F \& Ronald A (2011). Evidence that autistic traits show the same etiology in the general population and at the quantitative extremes $(5 \%, 2.5 \%$, and 1\%). Archives of General Psych 68(11): 1113-1121.

14. Heilbrun LP, Palmer RF, Jaen CR, Svoboda MD, Perkins J \& Miller CS (2015). Maternal chemical and drug intolerances: potential risk factors for autism and attention deficit hyperactivity disorder (ADHD). The $J$ Am Board Family Medi 28(4): 461-470.

15. Ko C, Kim N, Kim E, Song DH \& Cheon KA (2016). The effect of epilepsy on autistic symptom severity assessed by the social responsiveness scale in children with autism spectrum disorder. Behavioral and Brain Funct 12(1): 1-9.

16. Devnani, PA \& Hegde AU (2015). Autism and sleep disorders. $J$ Pedia Neurosci 10(4): 304.

17. Bandini LG, Anderson SE, Curtin C, Cermak S, Evans EW, Scampini R \& Must A (2010). Food selectivity in children with autism spectrum disorders and typically developing children. The $J$ Pedia 157(2): 259-264.

18. Nadon G, Feldman DE, Dunn W \& Gisel E (2011). Mealtime problems in children with autism spectrum disorder and their typically developing siblings: A comparison study. Autism 15(1): 98-113.

19. White SW, Simmons GL, Gotham KO, Conner CM, Smith IC, Beck KB \& Mazefsky CA (2018). Psychosocial treatments targeting anxiety and depression in adolescents and adults on the autism spectrum: Review of the latest research and recommended future directions. Curr Psych Rep 20(10): 82.

20. El-Ghoroury NH \& Krackow E (2011). A developmental-behavioral approach to outpatient psychotherapy with children with autism spectrum disorders. J Contemporary Psychother 41(1): 1117.

21. Must A, Phillips SM, Curtin C, Anderson SE, Maslin M, Lividini K \& Bandini LG (2014). Comparison of sedentary behaviors between children with autism spectrum disorders and typically developing children. Autism 18(4): 376-384.

22. Curtin C, Jojic M \& Bandini LG (2014). Obesity in children with autism spectrum disorders. Harvard Rev of Psych 22(2): 93.

23. Marí-Bauset S, Llopis-González A, Zazpe I, Marí-Sanchis A \& SuárezVarela MM (2016). Nutritional impact of a gluten-free casein-free diet in children with autism spectrum disorder. J Autism Devel Disord 46(2): 673-684.

24. Evans EW, Must A, Anderson SE, Curtin C, ScampiniR, Maslin M \& Bandini L (2012). Dietary patterns and body mass index in children with autism and typically developing children. Res in Autism Spectrum Disord 6(1): 399-405.

25. Shefa J (2018). Islam k, Rahaman MFU. Nutrient level \& its effect on cognition among ASD children in Bangladesh: a cross-sectional study. MOJ Pub Health 7(6): 266-272. 